\title{
Giant Cervical Kystic Lymphangioma in Children: Surgical Management of a Case
}

\author{
Youssouf Sidibé1,2,3*, Abdoulaye Kanté3,4, Amady Coulibaly3,5, Rokia Koné5, \\ Mamadou Koné6, Fatoumata Léonie François Diakité7, Drissa Ouattara ${ }^{4}$, \\ Abdoul Wahab Haidara', Boubacar Sanogo ${ }^{3}$, Sidiki Dao², N'faly Konate ${ }^{2}$, \\ Kadiatou Singaré Doumbia ${ }^{2,3}$, Samba Karim Timbo ${ }^{2,3}$, Mohamed Keita ${ }^{2,3}$, \\ Alhousseini Ag Mohamed2,3
}

${ }^{1}$ ENT and Head and Neck Surgery Department, CHU Mother-Child "Luxembourg", Bamako, Mali

${ }^{2}$ ENT and Head and Neck Surgery Department, CHU Gabriel Touré, Bamako, Mali

${ }^{3}$ Faculty of Medicine and Odontostomatology, Bamako, Mali

${ }^{4}$ Service of Surgery “B”, CHU Point G, Bamako, Mali

${ }^{5}$ Department of Stomatology and Maxillofacial Surgery, CHU-CNOS, Bamako, Mali

${ }^{6}$ Dermatology Department of the National Center for Disease Control Support (CNAM), Bamako, Mali

${ }^{7}$ Service of Paediatrics, CHU Gabriel Touré, Bamako, Mali

Email: *ysidibe2002@gmail.com

How to cite this paper: Sidibé, Y., Kanté, A., Coulibaly, A., Koné, R., Koné, M., Diakité, F.L.F., Ouattara, D., Haidara, A.W., Sanogo, B., Dao, S., Konate, N., Doumbia, K.S., Timbo, S.K., Keita, M. and Mohamed, A.A. (2019) Giant Cervical Kystic Lymphangioma in Children: Surgical Management of a Case. International Journal of Otolaryngology and Head \& Neck Surgery, 8, 1-6.

https://doi.org/10.4236/ijohns.2019.81001

Received: August 21, 2018

Accepted: November 26, 2018

Published: November 29, 2018

Copyright (c) 2019 by authors and Scientific Research Publishing Inc. This work is licensed under the Creative Commons Attribution International License (CC BY 4.0).

http://creativecommons.org/licenses/by/4.0/

\begin{abstract}
Introduction: Cervical cystic lymphangiomas are rare benign dysembryoplastic tumors of lymphatic origin. Its severity in the child is due on one hand to their fast evolution and the compression of the way aerodigestive and on the other hand, by the classical difficulty of their excision. The purpose of this work was to report a case of giant cervical cystic lymphangioma in a child to discuss the difficulties associated with its management in our context. Observation: This was a 3-year-old female child who was admitted to the ENT department of CHU "Luxembourg" for right lateral cervical swelling. The clinical examination had noted a large anterior-latero cervical swelling of soft, renitent, painless palpation, movable in relation to the superficial and deep plane, measuring about $20 \mathrm{~cm} \times 17 \mathrm{~cm}$, the skin was healthy. It wasn't particularity to the rest of the physical examination. The diagnosis of giant cervical cystic lymphangioma was discussed. Thorough excision of the swelling by right lateral cervicotomy was performed. Anatomopathological examination of the operative specimen confirmed the diagnosis. The postoperative course was simple and the evolution was favorable. Conclusion: Cervical cystic lymphangiomas are rare. Their management involves surgery, with short and long-term post-operative outcomes are often excellent.
\end{abstract}

\section{Keywords}

Kystic Lymphangioma, Cervical, Child, Bamako 


\section{Introduction}

Kystic lymphangiomas are rare benign dysembryoplastic tumors of lymphatic origin, which represent $2.6 \%$ to $5 \%$ of congenital cervical masses [1]. They return, with neurofibromas and hemangiomas in the context of hamartomas. They usually occur during childhood with $60 \%$ of cases before the first year of life [2] [3]. Of ubiquitous siege, their preferential localization is the posterior cervical triangle, with often mediastinal extension in $10 \%$ of cases [3]. The gravity of these tumoral formations in the child is due on one hand to their fast evolution and the compression of the way aerodigestive and on the other hand, by the classical difficulty of their excision [4] [5] [6].

The purpose of this work was to report a case of giant cervical cystic lymphangioma in a child to discuss the difficulties associated with its management in our context.

\section{Observation}

It was a 3-year-old female child, without particular pathological history, who was admitted on 15 December 2017 into the ENT department of CHU "Luxembourg" for a large anterior swelling. Lero-cervical right. This swelling was observed at the birth of the child and gradually increased in volume. There was no dyspnea, no dysphonia or dysphagia.

At the admission: on the general examination, the child had a good general condition with a Karnofski index at $90 \%$, a temperature at $36.5^{\circ} \mathrm{C}$, a weight at 12 $\mathrm{kg}$. On examination of the neck, he has marked bulky anterolateral-cervical tumefaction right soft, renitent, painless palpation, mobile relative to the superficial and deep, measuring about $20 \mathrm{~cm} \times 17 \mathrm{~cm}$, the skin was healthy looking (Figure 1).

There were no palpable cervicofacial or axillary lymphadenopathies. The rest of the physical exam was peculiar. Thus, the diagnostic hypothesis of a cervical cystic lymphangioma was mentioned. The cervical ultrasound performed showed a mass with multi-partitioned trans-sonic content of about $22 \mathrm{~cm}$ in diameter. The result of the cervico-thoracic computed tomography (CT) performed was in favor of a heterodense right anterolateral-cervical mass, a fluid component containing heterogenously enhanced daughter vesicles after injection of the contrast medium (Figure 2).

The cervical structures opposite are pushed back to the outside. The blood work done was without particularities. These elements made it possible to establish an operative indication. The intervention consisted of general anesthesia with orotracheal intubation in a cervicotomy according to Paul André's technique following a careful dissection of a soft rounded mass of fluid content adherent to the sternocleidomastoid muscle (Figure 3).

Ablation of the mass was obtained without nerve or vascular injury. The closure was carried out plan by plan after the installation of a Redon drain. Anatomopathological examination of the operative specimen confirmed the diagnosis 


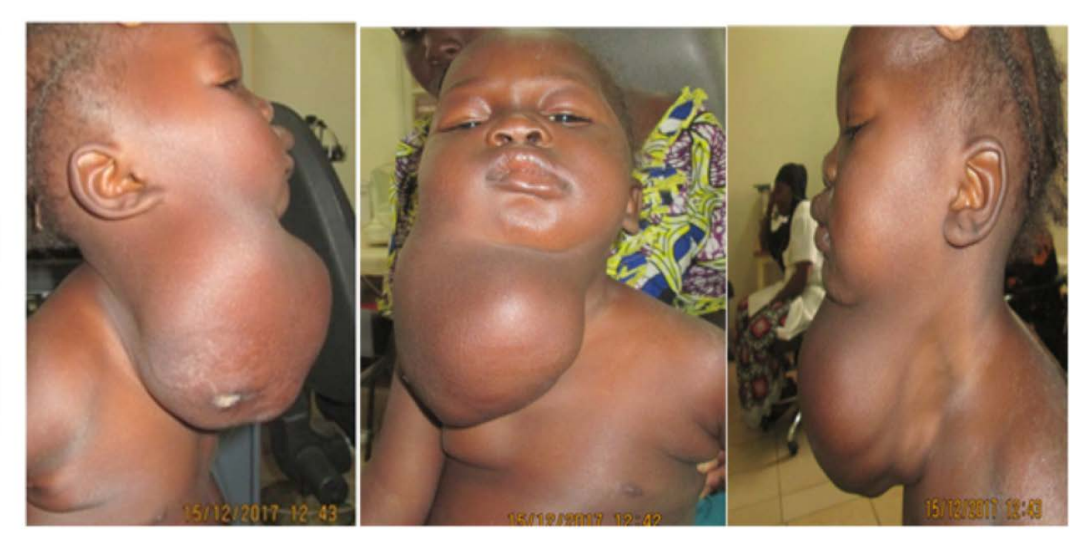

Figure 1. Child with a large right anterioleterocervical mass of soft consistency.

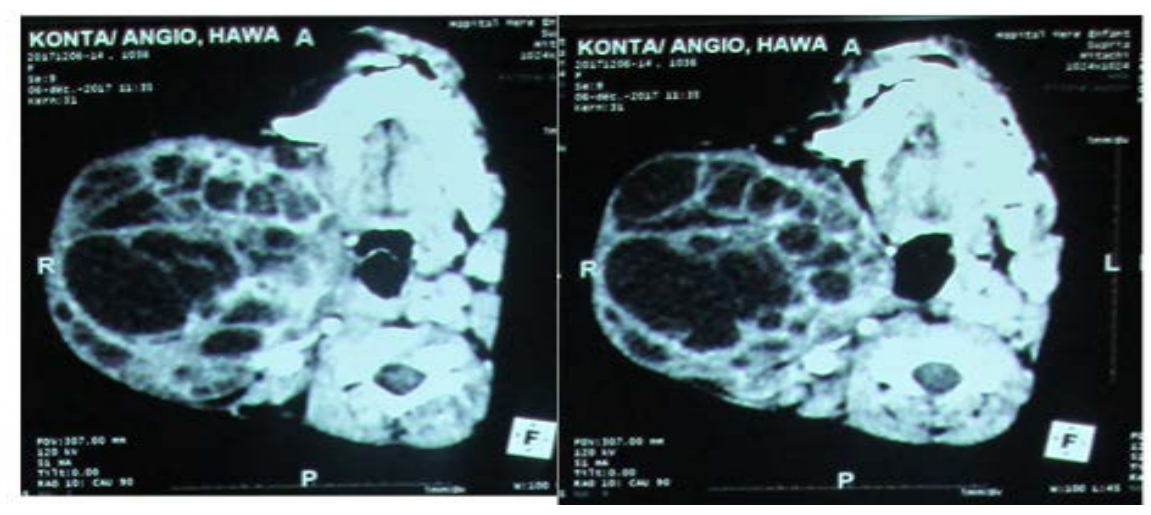

Figure 2. CT images in axial sections showing a multiple antero-collero-cervical mass multi compartmentalized, heterodense, fluid content.

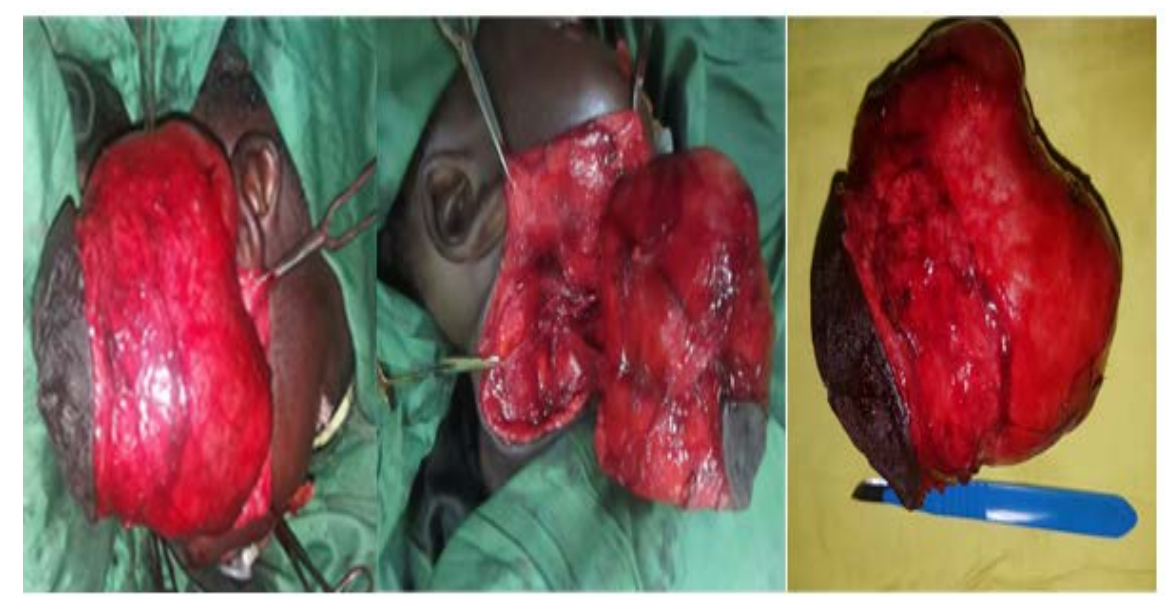

Figure 3. Intraoperative mass excision after careful dissection.

of cystic lymphangioma by showing a tumoral pluritissulaire formation with cysts papered by sometimes flattened cells, small strips of keratin of glands and by the foyers of bleeding and of inflammation (Figure 4). The postoperative course was simple and the evolution was favorable. Postoperative controls did not show recurrence one year later (Figure 5). 


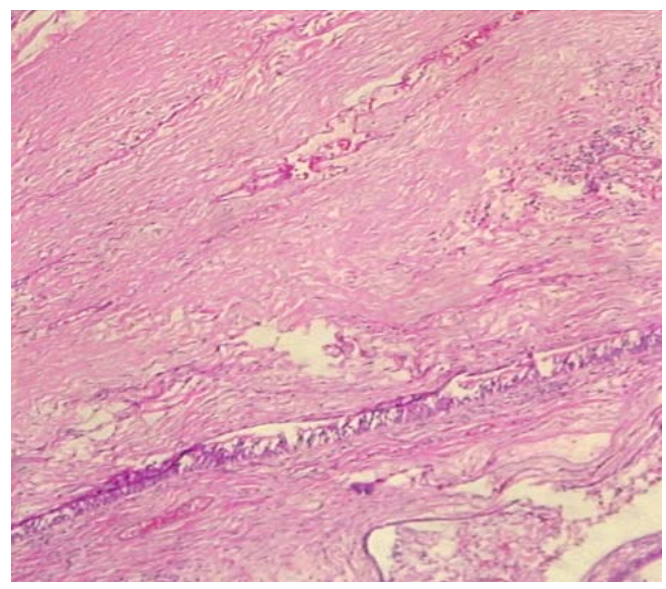

Figure 4. Histological aspect showing a tumoral training pluritissulaire with cysts papered by sometimes flattened cells, lamellas of keratin of glands and of the homes of bleeding and of inflammation.

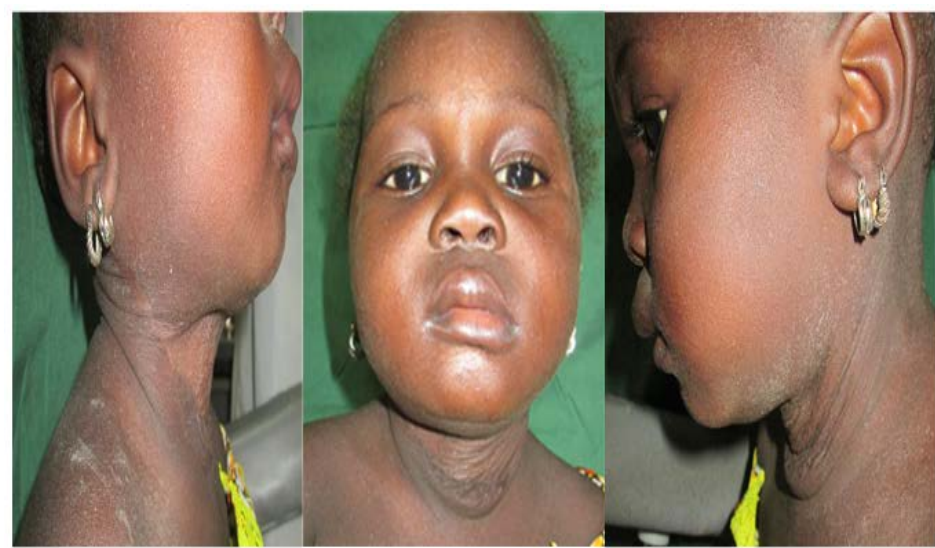

Figure 5. Post-operative images of the child one year later.

\section{Discussion}

Cystic lymphangiomas can be found in all parts of the body except the brain, but they affect most of the cervical area in about $75 \%$ of cases. Because of the latency of the disease, the discovery can be done at any age of life. However, children are most affected by cervical localization in about $90 \%$ [7]. The predominance of sex varies from one study to another [8] [9].

The symptomatology is a function of the size and topography of the kystic formations. Apart from the palpable cervical mass, cystic lymphangiomas have no clinical specificity. Thus, the circumstance of discovery is sometimes a revealing symptomatology such as the cervical mass as in this observation. Previous locations such as in the case reported are often asymptomatic, in contrast to posterior formations, frequently symptomatic by irritation and compression [10]. Physical signs are lacking or of little value, except in some large tumors well over a hemi-thorax. During the course of the disease, cystic lymphangiomas can become infected, presenting with inflammatory flares or intra-cystic haemorrhage, which is also a source of compression [4]. 
Medical imaging can evoke the diagnosis. Only histology allows a diagnosis of certainty [1] [2] [4]. Ultrasound shows a hypoechoic or anechoic appearance, sometimes with sediment or fine internal echoes and posterior reinforcement of echoes [10]. The cervical scanner is currently the reference examination, it shows a low density tumor ( $10-36 \mathrm{HU})$ but the septa are sometimes only revealed after injection of the contrast medium [11]. Magnetic resonance imaging seems to be useful for the exploration of this tumor but would prove to be less efficient than computed tomography especially in case of complications [7].

Therapeutically, many means are proposed such as chemical sclerosis, mediastinal drainage in mediastinal forms, surgery and even radiotherapy [2] [4]. The aim of surgical treatment is to perform complete excision of kystic lymphangiomas. The surgical indication is twofold, either in the case of an acute evolutionary accident resulting in a mediastinal compressive syndrome, or the usual uncertainty of the diagnosis in the asymptomatic patient. The obsession with malignancy, before which some observations have been reported, is a very accessory indication [4]. In the case reported, surgical treatment was indicated to establish the diagnosis of certainty and avoid the occurrence of complications. Given the difficulty of dissection because of the frequent infiltration, visceral adhesions to large vessels of the mediastinum, nerves or even the trachea, complete surgical excision is the only therapy to ensure a definitive cure. The approach is chosen based on localization and kystic extensions. Lateral cervicotomy is recommended by many authors for pure cervical localization. The cervico-mediastinal variety is useful when the seat of the lymphangioma is very anterior to the mediastinal stage [4]. In the case reported, the intervention did not cause any particular technical difficulties; there were no vascular or nervous sacrifices. The success of this intervention would also be explained by the fact that the cystic formation was well circumscribed with a cleavage plan. Sclerotherapy finds its indication at both ends of the natural evolution of kystic lymphangioma. A spontaneous regressive sclerosis is only described for small tumors [4]. This justifies the chemical sclerosis which could slow the evolution in the newborn and avoid a difficult surgical intervention. Some tumors are unresectable because of their size and location with a dangerous anatomical relationship or the general condition of the fragile patient, at high risk of surgery. These unresectable tumors can be treated alternatively by radiotherapy or chemical sclerosis [4].

\section{Conclusion}

Cervical kystic lymphangiomas are rare. The diagnosis suspected in clinical examination and medical imaging is only confirmed after the anatomopathological examination of the operative specimen. The management involves a fairly often complex surgery that remains effective despite the advent of sclerotherapy. Short- and long-term follow-up is often excellent.

\section{Conflicts of Interest}

We, authors of this article declare that there is no conflict of interests. 


\section{Consent of the Parental Rights}

We obtained the consent of the parents of the child for the publication of the images.

\section{References}

[1] Kaminopetros, P., Jauniaux, E., Kane, P., Weston, M., Nicolas, K.H. and Campbell, D. (1997) Prenatal Diagnosis of an Extensive Fetal Lymphangioma Using Ultrasonography, Magnetic Resonance Imaging and Cytology. The British Journal of Radiology, 70, 750-753. https://doi.org/10.1259/bjr.70.835.9245887

[2] Wunderbaldinger, P., Paya, K., Patrik, B., Turetschek, K., Hörmann, M., Horcher, E. and Bankier, A.A. (2000) CT and MRI of Generalized Cystic Lymphangiomatosis in Pediatric Patients. AJR, 174, 827-832. https://doi.org/10.2214/ajr.174.3.1740827

[3] Hoeffel, J.C., Adil, A., Mainard, L., Galloy, M., Arnould, V. and Ksiyer, M. (1996) Diagnosis of Mediastinal Lymphangiomas in Children. Revue des Maladies Respiratoires, 13, 287-293.

[4] Rakotosamimanana, J., Raharisolo Vololonantenaina, C.R., Ratovoson, H. and Ahmad, A. (2000) Cystic Cervico and Mediastinal Lymphangioma: A Case Report and Review of the Literature. Archives de P Institut Pasteur de Madagascar, 66, 61-64.

[5] Marrakchi, J., Zainine, Z., Akkari, S., Chahez, H., Chiboub, D., Beltaief, N. and Besbes, G. (2014) Contribution of Imaging in Cystic Lymphangioma. Annals of Cervico-Facial Pathology, 131, 122.

[6] Nadour, K. and Moujahid, M. (2016) Cervicothoracic Cystic Lymphangioma: About a Case. Pan African Medical Journal, 25, 189.

https://doi.org/10.11604/pamj.2016.25.189.9363

[7] Handa, R., Kale, R. and Upadhyay, K.K. (2004) Isolated Mediastinal Lymphangioma Herniatingthrough the Intercostal Space. Asian Journal of Surgery, 27, 241-242. https://doi.org/10.1016/S1015-9584(09)60042-7

[8] Uba, A.F. and Chirdan, L.B. (2006) Management of Cystic Lymphangioma in Children: Experience in Jos, Nigeria. Pediatric Surgery International, 22, 353-356. https://doi.org/10.1007/s00383-006-1642-7

[9] Ahmad, I., Alomari, M.D., Victoria, F., Karian, M.S., David Lord, M.D., Horacio, M., Padua, M.D., Patricia, E. and Burrows, M.D. (2006) Percutaneous Sclerotherapy for Lymphatic Malformations: A Retrospective Analysis of the Patient-Evaluated Improvement. Journal of Vascular and Interventional Radiology, 17, 1639-1648. https://doi.org/10.1097/01.RVI.0000239104.78390.E5

[10] Haenggeli, A., Becker, M., Crescentino, V., Kurt, A.M. and Lemann, W. (1997) Cervical Cystic Lymphangioma and Lymphangiomatosis: Case Presentation. Medicine and Hygiene, 55, 2088-1090.

[11] Poyraz, A.S., Kilic, D., Hatipoglu, A., Ozulku, M., Sar, A. and Bilezikci, B. (2004) Cystic Lymphangioma Confined to Mediastinum in Adult. The Japanese Journal of Thoracic and Cardiovascular Surgery, 52, 567-569.

https://doi.org/10.1007/s11748-004-0024-0 